\title{
SciDoc
}

Infer, Interpret \& Inspire Science

International Journal of Dentistry and Oral Science (IJDOS)

ISSN: $2377-8075$

\section{Post Extraction Complications - An Institution Based Retrospective Study}

Research Article

\section{Madhulaxmi $^{{ }^{*}}$, SohaibShahzan ${ }^{2}$}

${ }^{1}$ Professor, Department of Oral Surgery, Saveetha Dental College, Saveetha Institute of Medical and Technical Sciences (SIMATS), Saveetha University, Chennai 600077, India.

${ }^{2}$ Research assistant Dental Research Cell Saveetha dental college, Saveetha Institute of medical and Technical Sciences (SIMATS), Saveetha University, Chennai 600077, India.

\section{Abstract}

Tooth extraction is one of the most common procedures under taken in dental clinic. As with any surgical procedure, even a simple tooth extraction can result in complications. Post extraction complications can be annoying to the patient there by causing mild morbidity and have an impact in their quality of life. Complications are wide starting from common ones like alveolitis and root fracture, dry socket, infraction, halitosis, pain, trismus and uncommon ones like displacement of root fragments with in sinus and oral antral fistula. The aim of this study was to evaluate post extraction complications among patients visiting saveetha dental college. This is a retrospective study. We reviewed patient records and analysed the data of 86000 patients between June 2019 and March 2020. From a pooled sample size of 23000 extractions done during this period, data of patients reporting for post extraction complications were segregated and analysed. The statistical analysis was done using SPSS Version 20 by IBM. The results were analysed using chi-square test. In this study we observed that among a sample of 23000 simple extractions, only 42 patients had reported back with post extraction complications $(0.18 \%)$. These complications were more in males than females. When compared between maxillary and mandibular arch the mandible had more incidence with $54.16 \%$. The most common complication was dry socket (58.34\%). Pain as a complication was more in males than in females. With in the limits of study, the incidence of post extraction complication is more in males than females. Higher incidence of complication was seen in mandibular arch (54.16\%) than in maxillary arch (45.84\%).

Keywords: Teeth; Extraction; Complications; Pain; Dry Socket.

\section{Introduction}

Tooth extraction is one among the common procedures undertaken in dental clinics [27]. Post extraction complications generally don't occur, however there are times when the dentist is faced with post extraction complications [20]. Complications are unforeseen events that tend to extend from a specific operative procedure under normal circumstances [33].

Though they are rare, their occurrences results in a protracted phase of treatment, which is cumbersome to the patient and also to the clinician [19]. Thus it becomes imperative that the clinician is aware and recognises the entire spectrum of complications and their implications [30]. Complications are often wide, starting from common ones like alveolitis and root fracture to uncommon ones like displacement of a root fragment with in the sinus and oro-antralfistula [14]. Disturbed healing can also complicate or even jeopardize dental implant placement and other procedures [17]. Alveolar osteitis (AO) is the most common and most widely discussed in the literature and is sometimes confused with other less common complications [5]. Pain is a natural bodily response to noxious stimuli [13]. In post-extraction wound healing, pain is a key factor alerting patients to seek professional care out of concern for disturbed healing [26]. Normal uncomplicated alveolus healing has also been reported to cause moderate to severe pain [13]. The aim of this study was to analyze the incidence of post extraction complication among patients visiting Saveetha Dental College in a period of 1 year.

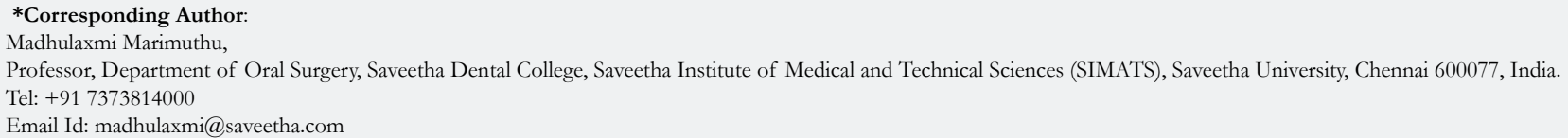

Copyright: Madhulaxmi Marimuthu 2021 . This is an open-access article distributed under the terms of the Creative Commons Attribution License, which permits unrestricted use, distribution and reproduction in any medium, provided the original author and source are credited. 


\section{Materials and Methods}

This is a retrospective study done among patients who visited Saveetha Dental college and Hospitals during the period June 2019 to March 2020. From a pooled sample size of 23000 extractions done during this period, data of patients reporting for post extraction complications were segregated and analysed. The approval for this university setting study was obtained from the Institution Ethics Board.

Inclusion criteria: Patients over 18 years, medically fit and healthy with no comorbidities, patients who reported with pain/ swelling/open extraction wound/difficulty in mouth opening and any other complaints after simple dental extraction.

Exclusion criteria: Patients less than 18 years, medically compromised patients and patients who underwent trans alveolar extractions.

We reviewed patient records and analysed the data of 86000 patients between June 2019 and March 2020. The parameters studied and tabulated included age, gender, teeth extracted and type of complications. The data was reviewed by 2 reviewers.

\section{Statistical Analysis:}

After further verification by an external reviewer, it was imported to the SPSS Version 20 by IBM for statistical analysis. Percentages, mean, standard deviation, frequency of parameter were employed in the analysis. Chi-square test was used to detect the significance between age, gender, site and various complications.

\section{Results and Discussion}

Post extraction complications were more in age group above 40 years. Bony spicules, pain management and dry socket were seen more in this age group. The most common complication in both age group was dry socket. There were 2 cases of trismus reported in age group below 40 years and 1 case in age group above 40 years (Graph 1).

Most complications were in mandibular arch than in maxillary arch (Graph 2). This can be attributed to the anatomical blood supply to maxilla vs the mandible. It can also be due to more extractions done in mandibular arch than the maxillary arch. Though this observation can be of clinical significance, there was no statistically significant difference in complications occurring in maxillary vs the mandibular.

Prevalence of complications were more in males than in females. Two cases of trismus were reported in males and one case in females. 3 cases of bony spicules were reported in males and 2 cases in females. Same number of cases of dry socket were reported in males and females (Graph 3).

Surgery and complications go hand in hand. Dental extraction is a minor surgical procedure which can lead to complications[24]. Although careful attention to surgical details, including proper patient preparation, asepsis and meticulous management of hard and soft tissue, controlled force when applying surgical instruments, hemostatis and adequate post operative instruction may help to reduce the rate of complications, though it has not been found to eliminate it [1].

The factors that contribute to such complications are numerous and include the patients compliance and general medical and oral health, difficulty of extraction, surgeons operative experience, etc. [34]. Other factors found to affect the complication rate include age and gender of patient [25].

The study sample included were patients mostly treated by den-

\section{Graph 1. Bar chart depicting the post extraction complications in different age groups.}

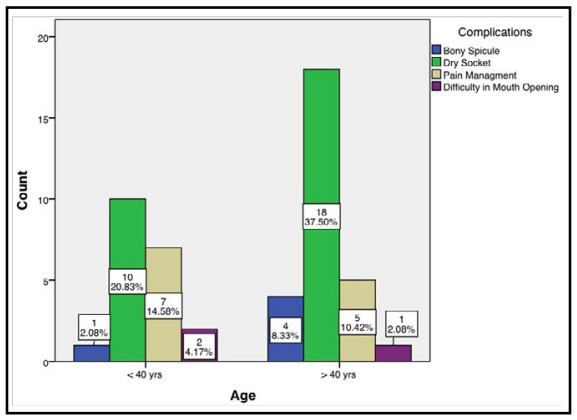

Graph 2. Bar chart depicting the distribution of post extraction complications in maxillary and mandibular arch.

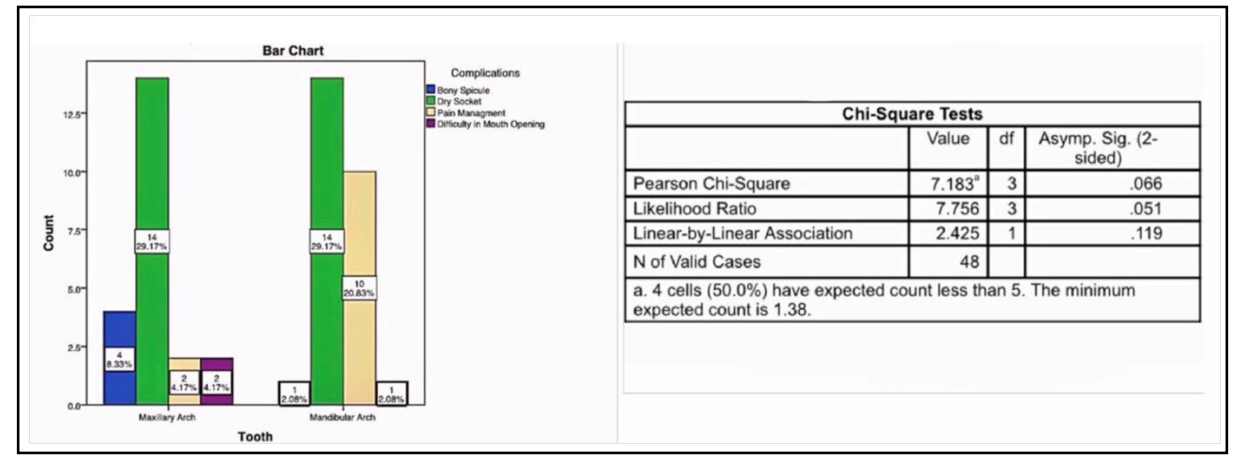


Graph 3. Bar chart depicting the post extraction complications in male and female patients.

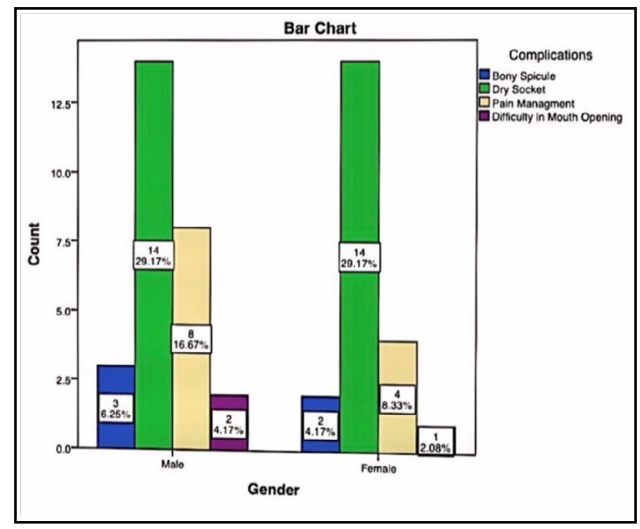

tal graduate students. As the study was done in a university setting, materials used for extraction, technique and post operative medications were standardised. The study shows higher incidence of dry socket $(58.34 \%)$, pain management $(25 \%)$, bony spicules(10.41), trismus $(6.25 \%)$.

Dry socket was the most common complication [3]. Similar results were observed in a study by Adeyemo et al [3]. In a histological study, Amler reported AO results from disturbances in the progression of healing from blood clot to granulation tissue [7]. Failure or interference in the mechanism of the granulation tissue development to replace the clots results in disintegration of the blood clot by putrefaction rather than by orderly resorption, giving rise to the well-known symptoms of dry socket [7].

Post operative pain management was more in males than in females. This may be due to various habits like smoking, alcohol, tobacco which are more common in males than in females [20]. And, also pain tolerance is generally said to be more in females than in males [1]. And, there are many studies which show that men more often complained of post operative pain than women [15]. Proper analgesic protocol can be taken to reduce pain [32]. Regardless of pain severity, one should seek to optimize "aroundthe-clock" dosages of these agents and then, if necessary, add an opioid to the regimen as needed for breakthrough pain [10].

The percentage of bony spicules was found to be $10.41 \%$. After tooth extraction, bone spicules should be removed, because they may result in an obstruction in placing a prosthetic restorative appliance [16]. Alveoloplasty can be done to remove bony spicules, prior to prosthetic rehabilitation [18].

Incidence of trismus was found to be $6.25 \%$. The factors contributing to trismus are: Low-grade infection post administration of local anesthetic agents [9]. Multiple needle penetrations correlate with a greater incidence of post injection trismus. This complication is especially noted when injections were given using barbed needle. The most commonly involved muscle is medial pterygoid during inferior alveolar nerve (IAN) block [9]. It has been hypothesised that trauma to this muscle, can cause microbleeding, hematoma formation and trismus. Elevation of flap beyond the external oblique ridge can also result in postoperative edema and there by pain and difficulty while opening the mouth [29].

At times, the patient hurts his/her own tongue or cheek under the effect of anesthesia resulting in reflex trismus [9]. Physiotherapy treatments may be required to establish normal function (exer- cises will include neck stretching, chin tuck, massaging of masticatory muscles, and other jaw stretching) [6]. Mandibular opening devices might be considered in some cases, but most likely provided by a physiotherapist or dental specialist [6].

Complications were more in age group above 40 the older adults than in age group below 40 the younger adults [4]. The possible reasons might be due to decreased healing potential and dense bone [31]. Increase in neurosensory problems in patients above 24 years was reported in a study [11]. Post extraction complications were more prevalent in males than in females. As mentioned earlier this may be due to various habits in males. However there are studies which show that complications are more in females than in males [8].

A higher incidence of complication was seen in extraction carried out in mandible (54.16\%) as compared to maxilla (45.84\%) [35]. This may be due to anatomical factors including dense cortical bone and comparatively lesser vascularity in mandible as compared to maxilla which has a good blood supply [35].

\section{Conclusion}

With in the limits of study, overall percentage of post extraction complications are significantly very minimal (0.18\%). Among those reported, post extraction complications are more in older males and affecting the mandibular arch $(54.16 \%)$. From this study, it can be inferred that proper surgical technique and protocols; post extraction instructions; patient compliance and motivation with good analgesics prescribed postoperatively, complications can be avoided to a great extent in simple extractions.

\section{References}

[1]. Abhinav RP, Selvarasu K, Maheswari GU, Taltia AA. The Patterns and Etiology of Maxillofacial Trauma in South India. Ann Maxillofac Surg. 2019 Jan-Jun;9(1):114-117. Pubmed PMID: 31293938.

[2]. Sweta VR, Abhinav RP, Ramesh A. Role of virtual reality in pain perception of patients following the administration of local anesthesia. Annals of maxillofacial surgery. 2019 Jan;9(1):110.

[3]. Adeyemo WL, Ladeinde AL, Ogunlewe MO. Clinical evaluation of postextraction site wound healing. J Contemp Dent Pract. 2006 Jul 1;7(3):40-9. Pubmed PMID: 16820806.

[4]. Ahuja, K. Complications and Risk Factor Associated with Extraction of Impacted Third Molars: A Prospective Study.

[5]. Akota I, Alvsaker B, Bjørnland T. The effect of locally applied gauze drain impregnated with chlortetracycline ointment in mandibular third-molar surgery. Acta Odontol Scand. 1998 Feb;56(1):25-9. Pubmed PMID: 9537731.

[6]. American Academy of Orofacial Pain. Orofacial Pain: Guidelines for As- 
sessment, Diagnosis, and Management. Quintessence Publishing Company, Incorporated.2013.

[7]. Amler MH. Disturbed healing of extraction wounds. J Oral Implantol. 1999;25(3):179-84. Pubmed PMID: 10551148.

[8]. Anyanechi CE, Saheeb BD. The complications associated with the extraction of asymptomatic impacted mandibular third molars: A prospective clinical study of 63 patients. J Neurol Neurosci. 2016;7(98):1-5.

[9]. Balakrishnan G, Narendar R, Kavin T, Venkataraman S, Gokulanathan S. Incidence of Trismus in Transalveolar Extraction of Lower Third Molar. J Pharm Bioallied Sci. 2017 Nov;9(Suppl 1):S222-S227. Pubmed PMID: 29284968 .

[10]. Becker DE. Pain management: Part 1: Managing acute and postoperative dental pain. Anesthesia progress. 2010;57(2):67-79.

[11]. Blondeau F, Daniel NG. Extraction of impacted mandibular third molars: postoperative complications and their risk factors. J Can Dent Assoc. 2007 May;73(4):325. Pubmed PMID: 17484797.

[12]. Capuzzi P, Montebugnoli L, Vaccaro MA. Extraction of impacted third molars. A longitudinal prospective study on factors that affect postoperative recovery. Oral Surg Oral Med Oral Pathol. 1994 Apr;77(4):341-3. Pubmed PMID: 8015796.

[13]. Cheung LK, Chow LK, Tsang MH, Tung LK. An evaluation of complications following dental extractions using either sterile or clean gloves. Int J Oral Maxillofac Surg. 2001 Dec;30(6):550-4. Pubmed PMID: 11829239.

[14]. Christabel A, Anantanarayanan P, Subash P, Soh CL, Ramanathan M, Muthusekhar MR, et al. Comparison of pterygomaxillary dysjunction with tuberosity separation in isolated Le Fort I osteotomies: a prospective, multi-centre, triple-blind, randomized controlled trial. Int J Oral Maxillofac Surg. 2016 Feb;45(2):180-5. Pubmed PMID: 26338075.

[15]. Cohen ME, Simecek JW. Effects of gender-related factors on the incidence of localized alveolar osteitis. Oral Surg Oral Med Oral Pathol Oral Radiol Endod. 1995 Apr;79(4):416-22. Pubmed PMID: 7614198.

[16]. Devaki VN, Balu K, Ramesh SB, Arvind RJ. Pre-prosthetic surgery: Mandible. Journal of pharmacy \& bioallied sciences. 2012 Aug;4(Suppl 2):S414.

[17]. Giglio JA, Rowland RW, Laskin DM, Grenevicki L, Roland RW. The use of sterile versus nonsterile gloves during out-patient exodontia. Quintessence Int. 1993 Aug;24(8):543-5. Erratum in: Quintessence Int 1995 Aug;26(8):533. Pubmed PMID: 8272491.

[18]. Vijayakumar Jain S, Muthusekhar MR, Baig MF, Senthilnathan P, Loganathan S, Abdul Wahab PU, et al. Evaluation of Three-Dimensional Changes in Pharyngeal Airway Following Isolated Lefort One Osteotomy for the Correction of Vertical Maxillary Excess: A Prospective Study. J Maxillofac Oral Surg. 2019 Mar;18(1):139-146. Pubmed PMID: 30728705.

[19]. Jesudasan JS, Wahab PU, Sekhar MR. Effectiveness of $0.2 \%$ chlorhexidine gel and a eugenol-based paste on postoperative alveolar osteitis in patients having third molars extracted: a randomised controlled clinical trial. $\mathrm{Br} \mathrm{J}$ Oral Maxillofac Surg. 2015 Nov;53(9):826-30. Pubmed PMID: 26188932.

[20]. Kumar S. Knowledge, attitude and awareness of dental undergraduate students regarding HIV/AIDS patients. Asian Journal of Pharmaceutical and Clinical Research. 2017:175.

[21]. Kumar S. Relationship between dental anxiety and pain experience during dental extractions. Asian Journal of Pharmaceutical and Clinical Research.
2017;10(3):458

[22]. Kumar $S$. The emerging role of botulinum toxin in the treatment of orofacial disorders: Literature update. Asian Journal of Pharmaceutical and Clinical Research. 2017;10(9):21-9.

[23]. Kumar S, Rahman RE. Knowledge, awareness, and practices regarding biomedical waste management among undergraduate dental students. Asian Journal of Pharmaceutical and Clinical Research. 2017;10(8):341.

[24]. Kumar, S. and Sneha, S. Knowledge and awareness regarding antibiotic prophylaxis for infective endocarditis among undergraduate dental students, Asian Journal of Pharmaceutical and Clinical Research. 2016; 154-159.

[25]. Bruce RA, Frederickson GC, Small GS. Age of patients and morbidity associated with mandibular third molar surgery. J Am Dent Assoc. 1980 Aug;101(2):240-5. Pubmed PMID: 6931159.

[26]. Marimuthu M, Andiappan M, Wahab A, Muthusekhar MR, Balakrishnan A, Shanmugam S. Canonical Wnt pathway gene expression and their clinical correlation in oral squamous cell carcinoma. Indian J Dent Res. 2018 MayJun;29(3):291-297. Pubmed PMID: 29900911.

[27]. Pacheco-Vergara MJ, Cartes-Velásquez RA. Referrals, procedures and complications in oral surgery services. Literature review. Revista Odontológica Mexicana. 2016 Jan 15;20(1):13-21.

[28]. Packiri S, Gurunathan D, Selvarasu K. Management of paediatric oral ranula: a systematic review. Journal of clinical and diagnostic research: JCDR. 2017 Sep;11(9):ZE06.

[29]. Patil SB, Durairaj D, Suresh Kumar G, Karthikeyan D, Pradeep D. Comparison of Extended Nasolabial Flap Versus Buccal Fat Pad Graft in the Surgical Management of Oral Submucous Fibrosis: A Prospective Pilot Study. J Maxillofac Oral Surg. 2017 Sep;16(3):312-321. Pubmed PMID: 28717289.

[30]. Patturaja K, Pradeep D. Awareness of Basic Dental Procedure among General Population. Research Journal of Pharmacy and Technology. 2016 Sep $1 ; 9(9): 1349$

[31]. Phillips C, White RP Jr, Shugars DA, Zhou X. Risk factors associated with prolonged recovery and delayed healing after third molar surgery. J Oral Maxillofac Surg. 2003 Dec;61(12):1436-48. Pubmed PMID: 14663809.

[32]. Rao TD, Kumar MS. Analgesic efficacy of paracetamol vs ketorolac after dental extractions. Research Journal of Pharmacy and Technology. 2018 Aug 1;11(8):3375-9.

[33]. Sheppard P. A Synopsis of Minor Oral Surgery (1997). George Dimitroulis. Publisher: Wright (Butterworth-Heinemann), Oxford. Price:£ 19.99. ISBN: 0-7236-1094-0.

[34]. Sisk AL, Hammer WB, Shelton DW, Joy ED Jr. Complications following removal of impacted third molars: the role of the experience of the surgeon. J Oral Maxillofac Surg. 1986 Nov;44(11):855-9. Pubmed PMID: 3464711.

[35]. Venkateshwar GP, Padhye MN, Khosla AR, Kakkar ST. Complications of exodontia: a retrospective study. Indian J Dent Res. 2011 SepOct;22(5):633-8. Pubmed PMID: 22406704. 